\title{
北半球副热带高压与极地海冰 的相互作用
}

\author{
方之芳 \\ (成都气象学院)
}

在高纬地区的海气相互作用中, 极地海冰有着突出的贡献. 近年来, 国内外气象学者研 究了极冰对某些地区的环流和天气的影响 ${ }^{[1,2]}$, 发现极冰不仅具有明显的局地效应, 而且可以 影响到中纬度甚至于另一半球的大气环流和天气. 极冰本身又是大气环流变化的结果. 冰气 相互作用具有滞后性. 本文应用统计方法, 讨论整个北半球区域极地海冰与副热带环流的相 关关系，指出冰气相互作用不仅具有时间滞后效应，而且具有明显的季节性和地区性，冰气之 间相互影响、相盲调整、形成复杂的厄.馈过程.

\section{一、资料和方法}

应用 Walsh 的 1953-1977 年逐年各月北极海冰覆盖面积资料. 北极海冰范围包括 $50^{\circ} \mathrm{N}$ 以北的北冰洋、北大西洋和北太平洋区域, 以北极为中心, 按经度将整个极区分为四个区域, $160^{\circ} \mathrm{E}-110^{\circ} \mathrm{W}$ 为 $\mathrm{A}$ 区, $110^{\circ} \mathrm{W}-20^{\circ} \mathrm{W}$ 为 $\mathrm{B}$ 区, $20^{\circ} \mathrm{W}-70^{\circ} \mathrm{E}$ 为 $\mathrm{C}$ 区, $70^{\circ} \mathrm{E}-160^{\circ} \mathrm{E}$ 为 $\mathrm{D}$ 区.

以某个月极冰覆盖面积减去后一个月极冰覆盖面积的值表示该月极冰融化凝结指数，该 指数反映极冰面积的月际变化.

北半球副高强度指数和西北太平洋副高强度指数取自国家气象中心长期组资料.

应用交叉相关函数方法, 将相关系数 $R$ 表示为 $t$ 和 $\tau$ 的函数 一 $R(t, \tau)$, 其中 $t$ 是作用 月份, $\tau$ 是响应的滞后月数,构成时滞相关矩阵 $\boldsymbol{R}$.

求算北半球极冰面积和极冰融化凝结指数与副热带高压强度指数之间的时滞相关矩阵, 各区域极冰覆盖面积与西北太平洋副高强度之间的时滞相关矩阵，从中分析北极海冰与大气 环流的相互作用.

\section{二、极冰对大气环流的时滞相关}

以全区极冰面积作用月份 $(t)$ 为纵坐标, 以北半球副高强度滞后月数 $(\tau)$ 为横坐标, 列 出极冰面积与大气环流的时滞相关矩阵 $\boldsymbol{R}_{I A}$ (图 $1 \mathrm{a}$ ). 因当 $|R|=0.396$ 时, 通过 $\alpha=0.05$ 的相关检验, 故 $|R| \geqslant 0.4$, 认为相关显著, 从 $|R|=0.3$ 起, 每隔 0.1 分析一条等值线, 分 析相关范围较大, 而且存在绝对值大于 0.4 的区域。

图 1a 表明, 北极海冰对北半球副高强度的相关关系存在敏感期,时间是冬季. 初冬(十一 月至十二月)的极冰, 与当时及后一个月的副高强度呈明显负相关, 相关, 系数达 - 0.48. 整个

本文 1985 年 1 月7 日收到. 

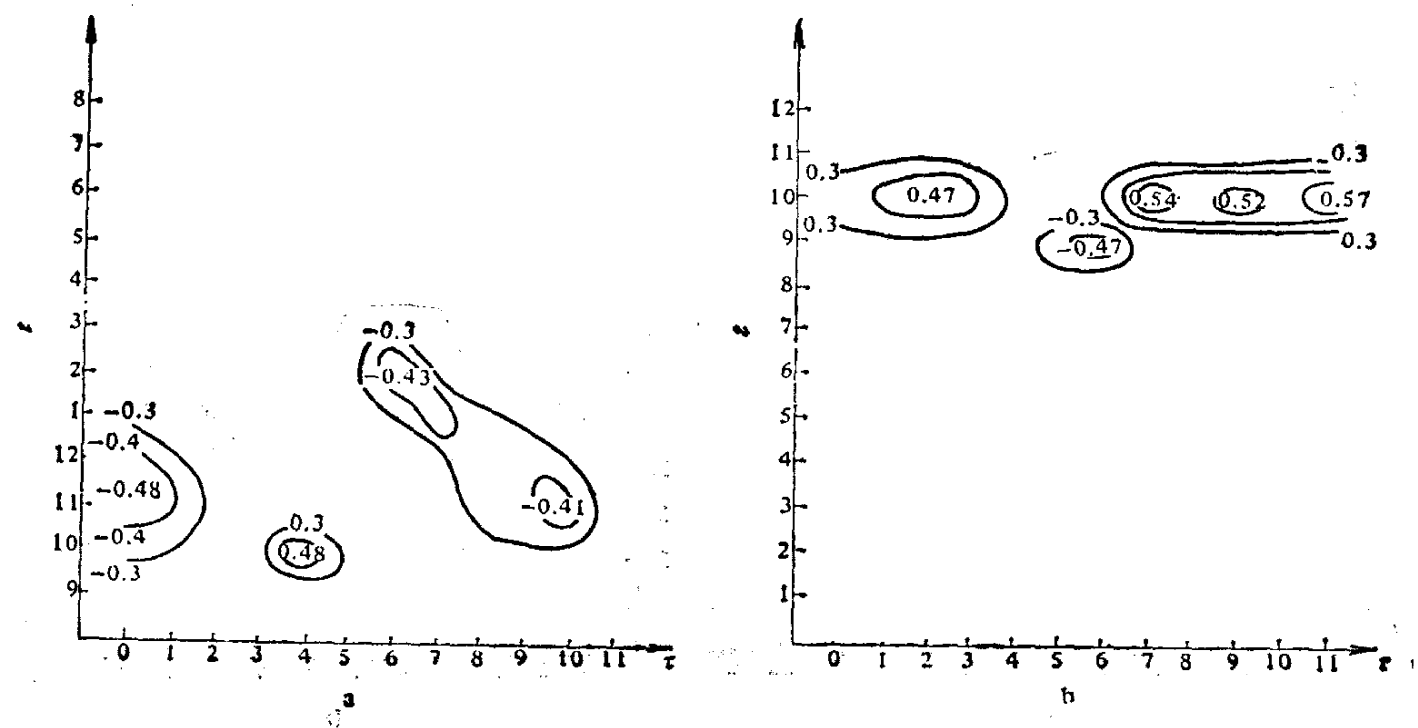

图 1 极冰对大气环流的时滞相关矩阵图

a. $\boldsymbol{R}_{I A} ;$ b. $\boldsymbol{R}_{M A}$

冬季(十一月至二月)的极冰与夏季八、九月份的副高亦有明显负相关，反映为冬季极冰强，则 夏季副高较弱. 而三月至十月，极冰与当时或滞后的副热带环流的相关关系甚微.

以极冰融化凝结指数作用月份 $(t)$ 为纵坐标, 以副高强度滞后月数 $(\tau)$ 为横坐标, 列出 极冰融化凝结指数与副热带环流的时滞相关矩阵 $\boldsymbol{R}_{M A}$ (图 1b). 图 $1 \mathrm{~b}$ 表明,极冰融化凝结指 数与副热带环流的相关关系存在一个关键月份，时间是十月. 十月极冰的凝结值影响初冬 (十 一月、十二月)副热带环流，更明显影响夏季五至九月的副高强度,呈正相关,相关系数达 0.57 . 由于十月是凝结期, 融化凝结指数为负值,正相关表示若十月极冰凝结多, 则后期副高强度较 弱.

对照图 $1 a$ 和图 $l b$ ，可见相关区是一一对应的,因而认为十月极冰的凝结值，奠定了冬季 极冰面积的基础. 极冰对环流的影响存在季节性和滞后性.

以各区极冰面积作用月份 $(t)$ 为纵坐标, 以西北太平洋副热带高压强度滞后月数 $(\tau)$ 为 横坐标，列出各区极冰面积与西北太平洋副高强度的时滞相关矩阵（图 2). 图 2a 表示 A区 极冰覆盖面积与西北太平洋副高的相关关系,其中有一个相关区范围较大,等值线走向与主对 角线几乎平行，表示从一月至五月的 A 区极冰面积与夏季七月的西北太平洋副高强度呈负相 关关系, 相关系数达 - 0.61. 反映若冬春 $\mathrm{A}$ 区极冰覆盖面积大, 则当年夏季七月西北太平洋副 高较弱.

图 $2 b$ 表示 B 区极冰面积与西北太平洋副高的相关关系，一月至四月的极冰与夏季七月的 副高强度呈负相关, 相关系数达 -0.53 .

图 2c 表示准东半球 (C区和 D区总和)极冰覆盖面积与西北太平洋副高的相关关系，一月 至三月极冰与六月的副高强度呈正相关,相关系数达 0.58. 由此可见,东西半球的极冰面积与 夏季西北太平洋副高强度的相关关系各不相同，准西半球的春冬海冰与七月副高呈负相关,准 东半球的春冬海冰与六月副高呈正相关. 

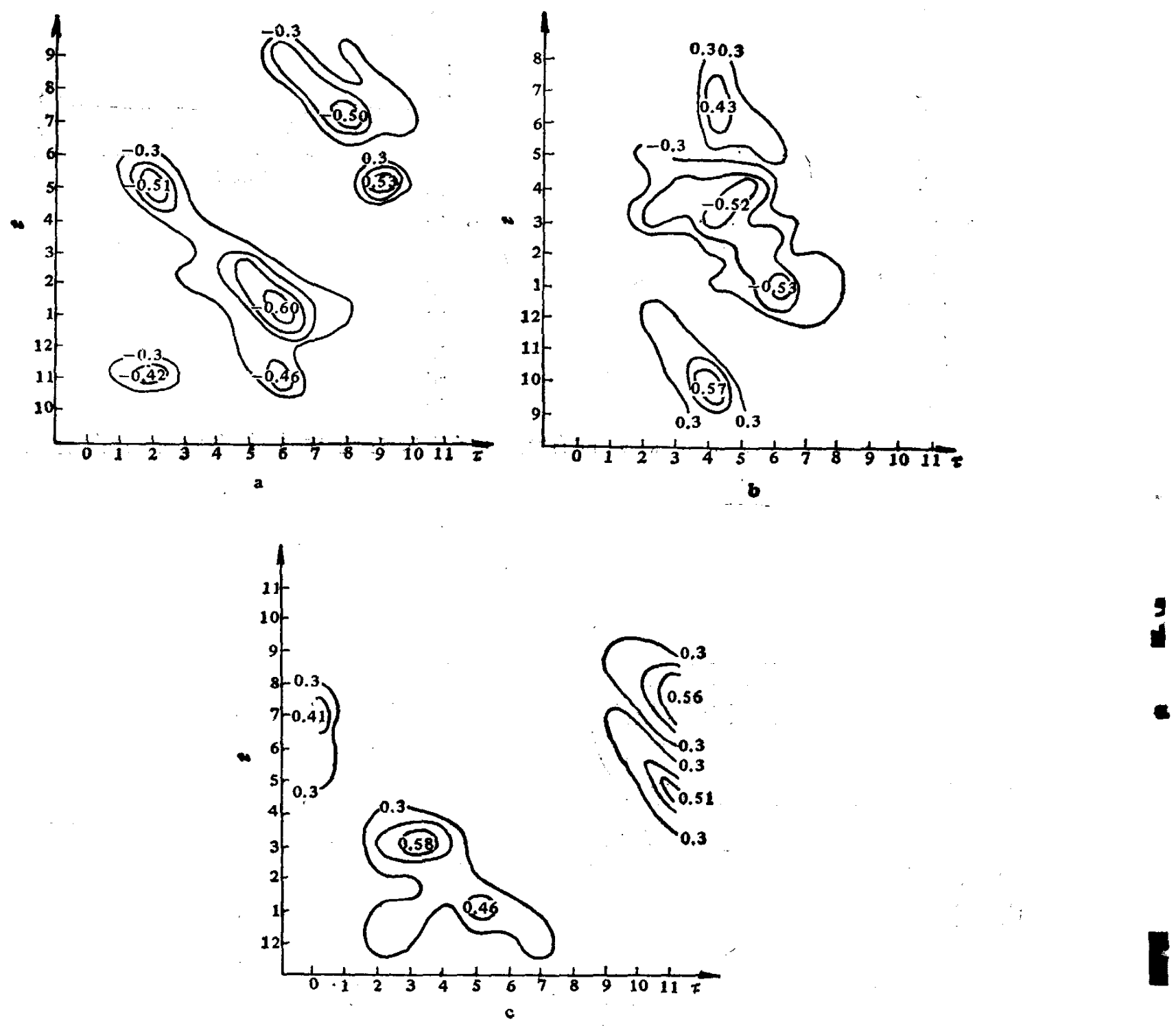

图 2 各区极冰面积对西北太平洋高压强度的时滞相关矩阵图

a. 区域 A; b. 区域 B; c. 区域 C 和D的总和

\section{三、大气环流对极冰的时带相关}

以北半球副热带高压出现月份 $(t)$ 为纵坐标, 以全区极冰面积滞后月数 $(\tau)$ 为横坐标, 列出大气环流与极冰面积的时滞相关矩阵 $\boldsymbol{R}_{A I}$ (图 3a).

从图上可见,存在三个关系密切的相关区,有一个相关区范围相当大，等值线走向与矩阵 主对角线近乎平行. 这个相关区表示从五月至九月,即整个夏季的副高与整个冬季(十一月至 第二年二月)的极冰面积存在密切相关,在相关区的中心,系数高达 -0.69 .表示冬季极冰面积 在很大程度上受夏季副高的制约,北半球夏季副高强,则影响其后的冬季极冰,使之面积缩小.

比较图 $1 \mathrm{a}$ 和图 3a 可见,对北半球而言, 夏季环流与冬季极冰的相关远远大于冬季极冰与 夏季环流的相关. 极冰的异常,引起环流的异常,而环流的异常, 又导致极冰的异常,它们相互 

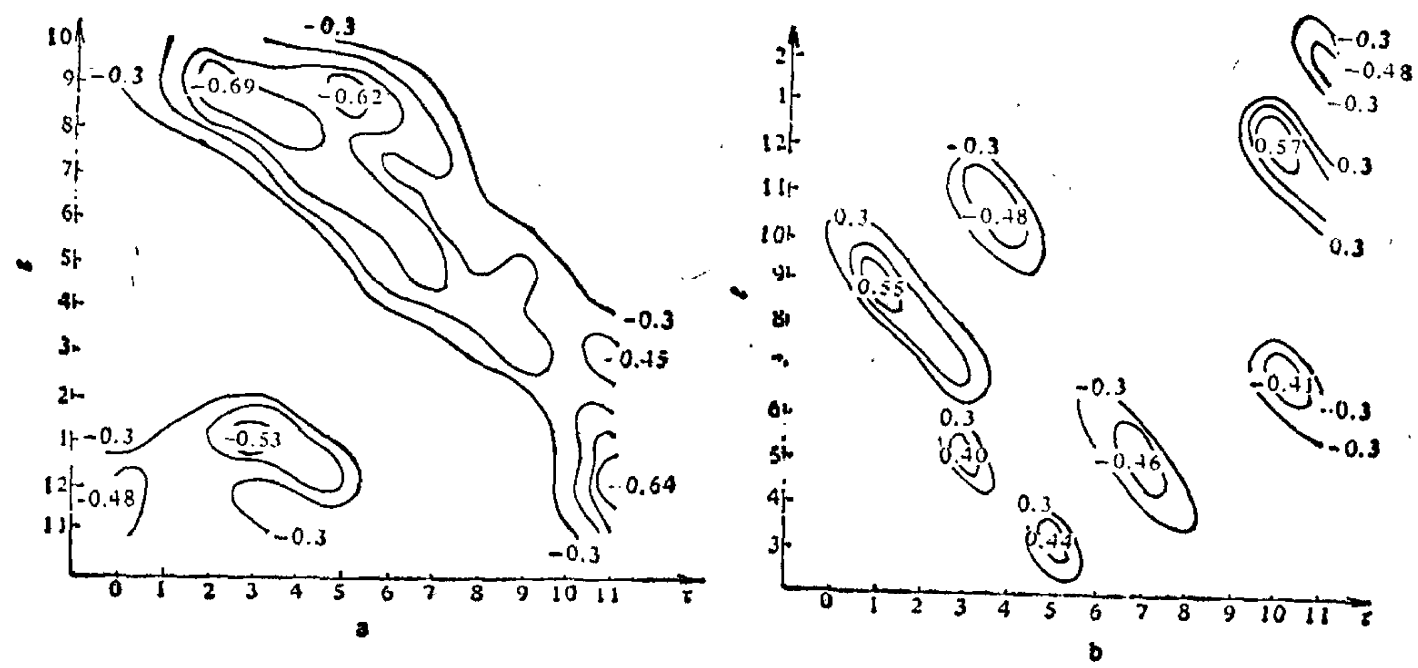

图 3 大气环流对极冰的时滞相关矩阵图

a. $R_{A I} ; \quad$ b. $R_{M A}$

影响、相互调整、相互反馈, 互为因果, 但在整个影响作用过程中, 夏季副高是处于主导地位,冬 季极冰仅仅是影响夏季副高的因子之一。

以副高强度作用月份 $(t)$ 为纵坐标, 以极冰融化凝结指数滞后月数 $(\tau)$ 为横坐标, 列出 大气环流与极冰融化凝结指数时滞相关矩阵 $\boldsymbol{R}_{A M}$ (图 3b).

图中可见等值线走向与主对角线平行,最明显的一个相关区时间是七月至九月,七至九月 的副高强度与十月极冰增长值呈正相关,相关系数是 0.55 . 十月份极冰融化凝结指数为负值, 正相关表示七至九月副高越强,则推迟十月极冰的凝结,使十月极冰增长面积较小。其原因可 能与海洋能量贮存有关。

\section{四、小 结}

根据以上相关分析事实,本文提出以下几点看法:

1. 北半球极地海冰与副热带环流的相互作用具有明显的滞后性和季节性. 时间上滞后可 达半年甚至于一年,季节上表现为冬季是极冰作用期,夏季是副高作用期.

2. 东西半球春冬季极冰对夏季西北太平洋副高的作用各不相同。西半球极冰面积与夏季 七月太平洋副高呈负相关,东半球极冰面积与六月太平洋副高是正相关。

3. 北半球冬季极冰与夏季副高存在负相关,夏季副高又与其后冬季极冰面积呈负相关,极 冰与副高之间构成正反馈 , 但在整个作用过程中,夏季副高处于主导地位.

\section{参考文献}

[1] Walsh, J. E., Interannual atmospheric variability and associated fluctuations in arctic sea ice extent, Journal of Geophysical Reaserch, 84 (1979), c. 11:6915-6928.

[2]符淙斌,我国长江流域梅雨变动与南极冰雪状况的可能联系,科学通报，26(1981)，8：484-486。 